\title{
Plasmonic versus dielectric enhancement in thin-film solar cells
}

\author{
Dühring, Maria Bayard; Mortensen, N. Asger; Sigmund, Ole
}

\section{Published in:}

Applied Physics Letters

Link to article, DOI:

$10.1063 / 1.4719203$

Publication date:

2012

Document Version

Publisher's PDF, also known as Version of record

Link back to DTU Orbit

\section{Citation (APA):}

Dühring, M. B., Mortensen, N. A., \& Sigmund, O. (2012). Plasmonic versus dielectric enhancement in thin-film solar cells. Applied Physics Letters, 100(21), 211914. https://doi.org/10.1063/1.4719203

\section{General rights}

Copyright and moral rights for the publications made accessible in the public portal are retained by the authors and/or other copyright owners and it is a condition of accessing publications that users recognise and abide by the legal requirements associated with these rights.

- Users may download and print one copy of any publication from the public portal for the purpose of private study or research.

- You may not further distribute the material or use it for any profit-making activity or commercial gain

- You may freely distribute the URL identifying the publication in the public portal 


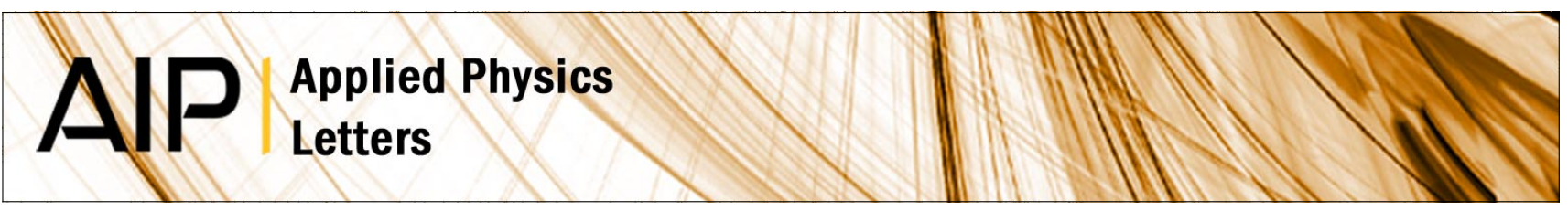

\section{Plasmonic versus dielectric enhancement in thin-film solar cells}

Maria B. Dühring, N. Asger Mortensen, and Ole Sigmund

Citation: Appl. Phys. Lett. 100, 211914 (2012); doi: 10.1063/1.4719203

View online: http://dx.doi.org/10.1063/1.4719203

View Table of Contents: http://apl.aip.org/resource/1/APPLAB/v100/i21

Published by the American Institute of Physics.

\section{Related Articles}

Response to "Comment on 'Open-circuit voltage dependency on hole-extraction layers in planar heterojunction organic solar cells"' [Appl. Phys. Lett. 100, 266101 (2012)]

Appl. Phys. Lett. 100, 266102 (2012)

A new architecture for solar cells involving a metal bridge deposited between active TiO2 particles

J. Appl. Phys. 111, 123109 (2012)

Fabrication of solution-processed hydrogenated amorphous silicon single-junction solar cells

Appl. Phys. Lett. 100, 253908 (2012)

Minimizing interfacial losses in inverted organic solar cells comprising Al-doped $\mathrm{ZnO}$

Appl. Phys. Lett. 100, 253903 (2012)

Very high open-circuit voltage of $5.89 \mathrm{~V}$ in organic solar cells with 10 -fold-tandem structure

Appl. Phys. Lett. 100, 243302 (2012)

\section{Additional information on Appl. Phys. Lett.}

Journal Homepage: http://apl.aip.org/

Journal Information: http://apl.aip.org/about/about_the_journal

Top downloads: http://apl.aip.org/features/most_downloaded

Information for Authors: http://apl.aip.org/authors

\section{ADVERTISEMENT}

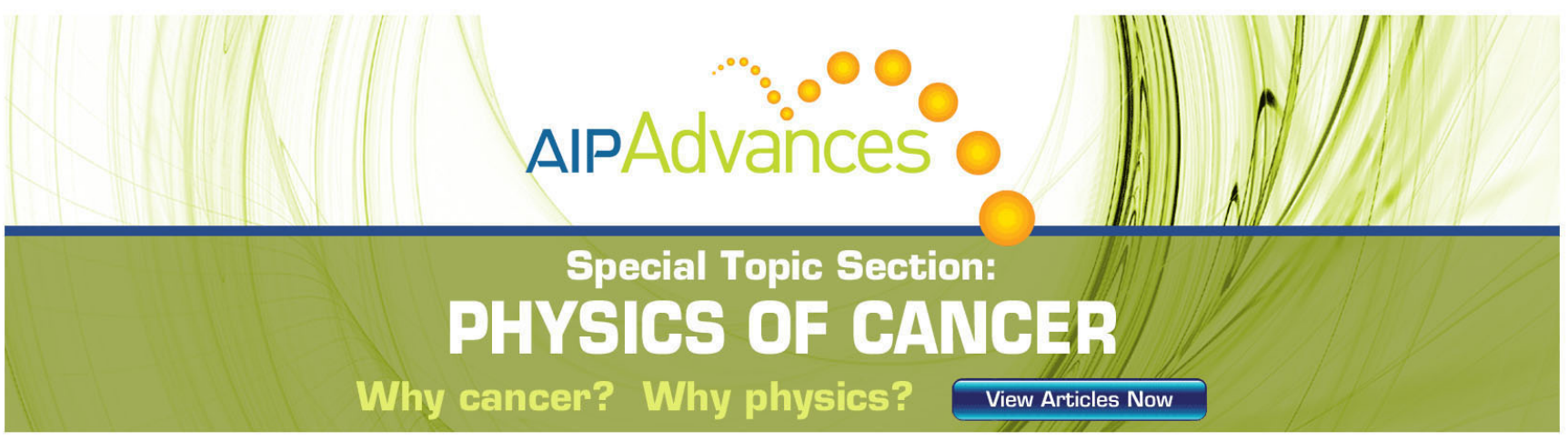




\title{
Plasmonic versus dielectric enhancement in thin-film solar cells
}

\author{
Maria B. Dühring, ${ }^{1}$ N. Asger Mortensen, ${ }^{2}$ and Ole Sigmund ${ }^{1, a)}$ \\ ${ }^{1}$ Department of Mechanical Engineering, Solid Mechanics, Technical University of Denmark, \\ Niels Koppels Allé, B. 404, DK-2800 Lyngby, Denmark \\ ${ }^{2}$ Department of Photonics Engineering, Technical University of Denmark, Ørsteds Plads, B. 343, \\ DK-2800 Lyngby, Denmark
}

(Received 22 May 2011; accepted 1 May 2012; published online 24 May 2012)

\begin{abstract}
Several studies have indicated that broadband absorption of thin-film solar cells can be enhanced by use of surface-plasmon induced resonances of metallic parts like strips or particles. The metallic parts may create localized modes or scatter incoming light to increase absorption in thin-film semiconducting material. For a particular case, we show that coupling to the same type of localized slab-waveguide modes can be obtained by a surface modulation consisting of purely dielectric strips. The purely dielectric device turns out to have a significantly higher broadband enhancement factor compared to its metallic counterpart. We show that the enhanced normalized short-circuit current for a cell with silicon strips can be increased 4 times compared to the best performance for strips of silver, gold, or aluminium. For this particular case, the simple dielectric grating may outperform its plasmonic counterpart due to the larger Ohmic losses associated with the latter. (C) 2012 American Institute of Physics. [http://dx.doi.org/10.1063/1.4719203]
\end{abstract}

The discovery of extraordinary optical transmission through subwavelength apertures in metal films ${ }^{1}$ has lead to intense studies of plasmonic structures during the last decade. $^{2}$ The extreme light concentration of plasmonic structures has been used in a range of applications such as sensors, ${ }^{3}$ optical lenses, ultrafast and compact photodetectors and modulators, near-field scanning optical microscopy, and in nonlinear optics. ${ }^{4}$

Plasmon excitation and light localization have been used to enhance the optical absorption in a number of different thin-film photodetectors and solar cell structures. ${ }^{5,6}$ Reference 7 suggests a systematic approach to increase the absorption in a thin Si film over the solar spectrum by distributing $\mathrm{Ag}$ strips on top of a $\mathrm{SiO}_{2}$-coated $\mathrm{Si}$ film on a $\mathrm{SiO}_{2}$ substrate. The $\mathrm{Ag}$ strips scatter the incident wave and allow the coupling to slab-waveguide modes in the Si thin-film. It is shown that the normalized short-circuit current for the solar spectrum is enhanced by more than $40 \%$ compared to a bare dielectric surface. Similar conclusions for other plasmonic configurations are seen in, e.g., Refs. 8 and 9. It is well-known, however, that purely dielectric gratings also may enhance absorption, ${ }^{10}$ but direct comparisons between dielectric and plasmonic enhancement are rarely seen. As a strong alternative to plasmonic structures, Brongersma group has recently proposed and demonstrated a solution where semiconductor-based nanowires are used to couple the incident light into the same type of Si slab-waveguide modes. ${ }^{11}$ In this Letter, we further challenge this idea and show examples where dielectric structures outperform their metallic counterparts.

We examine a periodic solar cell structure similar to the one from Ref. 7. The performance of the structure for three different metal strips ( $\mathrm{Ag}, \mathrm{Au}$, and $\mathrm{Al}$ ) is compared to the performance when the strips consist of either $\mathrm{Si}$ or $\mathrm{SiO}_{2}$. It is

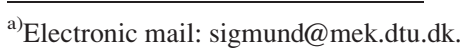

shown that the normalized short-circuit current for the solar spectrum is significantly larger and increased by up to $168 \%$ when strips of $\mathrm{Si}$ are used instead of the three different metals. It appears that the same optical mode localizations in the absorbing Si film are obtained for Si strips compared to metal strips, but without the undesired additional energy loss associated with the latter. This shows that the predominant enhancement for this particular case does not come from plasmon-mediated field enhancement, but rather from coupling made possible by the structured surface itself. Clearly, when benchmarking the performance of plasmon-enhanced absorption in planar Si thin films, attention should be paid also to the alternative of metallic structuring, such as surface-structuring of the Si itself.

The geometry of the periodic solar cell is shown in Fig. 1. A numerical model of the cell is based on full-wave finite element frequency domain (FEFD) simulations using COMSOL. ${ }^{12}$ The direction of the incoming optical wave,

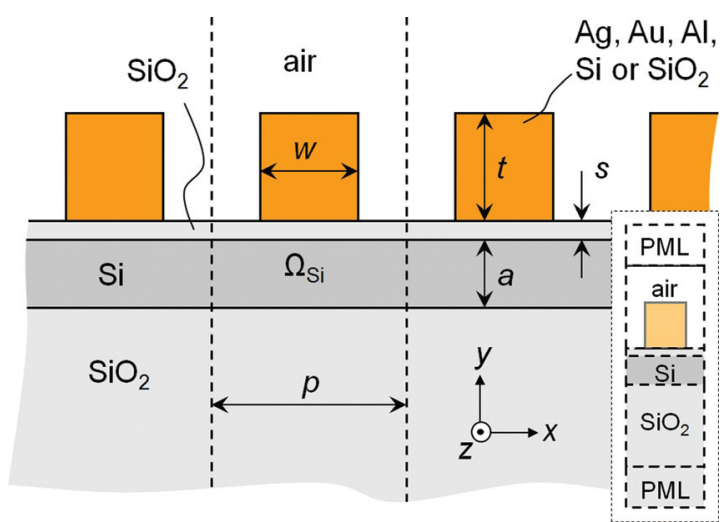

FIG. 1. The periodic solar cell structure with period $p$. The strip on the surface with thickness $t$ and width $w$ can consist of the 5 different materials Ag, $\mathrm{Au}, \mathrm{Al}, \mathrm{Si}$, and $\mathrm{SiO}_{2}$. The structure is illuminated from above at normal incidence with either $E_{z}$ or $H_{z}$ polarization. The insert in the lower right corner outlines the periodic modeling domain including PML regions. 
governed by the time-harmonic Helmholtz equation, ${ }^{13}$ is perpendicular to the surface. The Si layer $\Omega_{\mathrm{Si}}$ with thickness $a=50 \mathrm{~nm}$ absorbs a part of the optical energy calculated by the expression $\left(\Omega_{\mathrm{Si}}\right.$ excludes the Si strips in case of dielectric gratings)

$$
\Phi=\frac{1}{2} \omega \varepsilon_{0} \Im\left(\varepsilon_{r}\right) \int_{\Omega_{\mathrm{Si}}}|E|^{2} \mathrm{~d} \mathbf{r},
$$

where $\omega$ is the angular frequency, $\varepsilon_{0}$ is the vacuum permittivity, $\varepsilon_{r}$ is the relative permittivity of the material, and $E$ is the electric field. The top and bottom part of the cell is terminated by perfectly matched layers (PML), see Ref. 14 and the insert in Fig. 1, and the left and right boundaries are periodic with a period $p$ that can vary. The strip at the surface of the solar cell with thickness $t=60 \mathrm{~nm}$ and width $w=80 \mathrm{~nm}$ can consist of the 5 individual materials $\mathrm{Ag}, \mathrm{Au}, \mathrm{Al}, \mathrm{Si}$, and $\mathrm{SiO}_{2}$. When the strips consist of $\mathrm{Si}$, the thin layer of $\mathrm{SiO}_{2}$ with thickness $s=10 \mathrm{~nm}$ is removed between the strip and the $\mathrm{Si}$ layer. The thickness of the $\mathrm{SiO}_{2}$ substrate is $200 \mathrm{~nm}$.

The absorption enhancement plots in $\Omega_{\mathrm{Si}}$ for each of the 5 strip materials compared to a cell with a bare surface is calculated as function of the reciprocal lattice constant and the photon energy. The wavelength dependent dielectric constant $\varepsilon_{r}$ for $\mathrm{Si}$ is taken from Ref. 15; for $\mathrm{SiO}_{2}$, it is found in Ref. 16, and the values for the metals are from Ref. 17. The absorption enhancements for the cell with an $\mathrm{Ag}$ strip for $E_{z}$ and $H_{z}$-polarized light are plotted in Figs. 2(a) and 2(c), respectively. The color scale is logarithmic, and areas between green and red indicate situations where the absorption is larger than for a bare surface. The plots correspond well to the plots in Ref. 7, and the small differences are due to different numerical methods used and possibly slightly different choices of material values and geometry parameters. When the enhancements are plotted for $\mathrm{Au}$ and $\mathrm{Al}$ strips, the plots are similar to the ones for Ag. This indicates that the three metals result in the same effects and are coupling to the same slab-waveguide modes. The corresponding absorption enhancements are plotted for $\mathrm{Si}$ strips in Figs. 2(e) and 2(g). Compared to Ag strips, a greater part of the parameter spaces exhibit enhancement (values larger than 1) when Si strips are employed. Especially for decreasing values of $p$, where the gaps between the strips become small and for smaller wavelengths, Si tends to perform better, since less energy goes to Ohmic losses for the Si grating. That Ohmic losses are dominant for the metal grating is demonstrated in Figs. 2(b), 2(d), 2(f), and 2(h), which show the corresponding relative losses for $E_{z}$ and $H_{z}$-polarized light in the metal and dielectric strips, respectively. Clearly, the losses are almost negligible over a large part of the spectrum for the $\mathrm{Si}$ case, but rather dominant for the Ag case. For $E_{z^{-}}$ polarization, the loss in the Si strips (Fig. 2(f)) is somewhat high for smaller wavelengths, however, when integrated over the solar intensity spectrum, this does apparently not degrade the overall performance. A reflection/transmission study of the two types of gratings reveals that these properties are rather similar, at least for the larger grating periods where best absorption is observed. This proves that the main difference between the dielectric and metallic gratings is the Ohmic loss. Another observation is that the structures of $\mathrm{Si}$
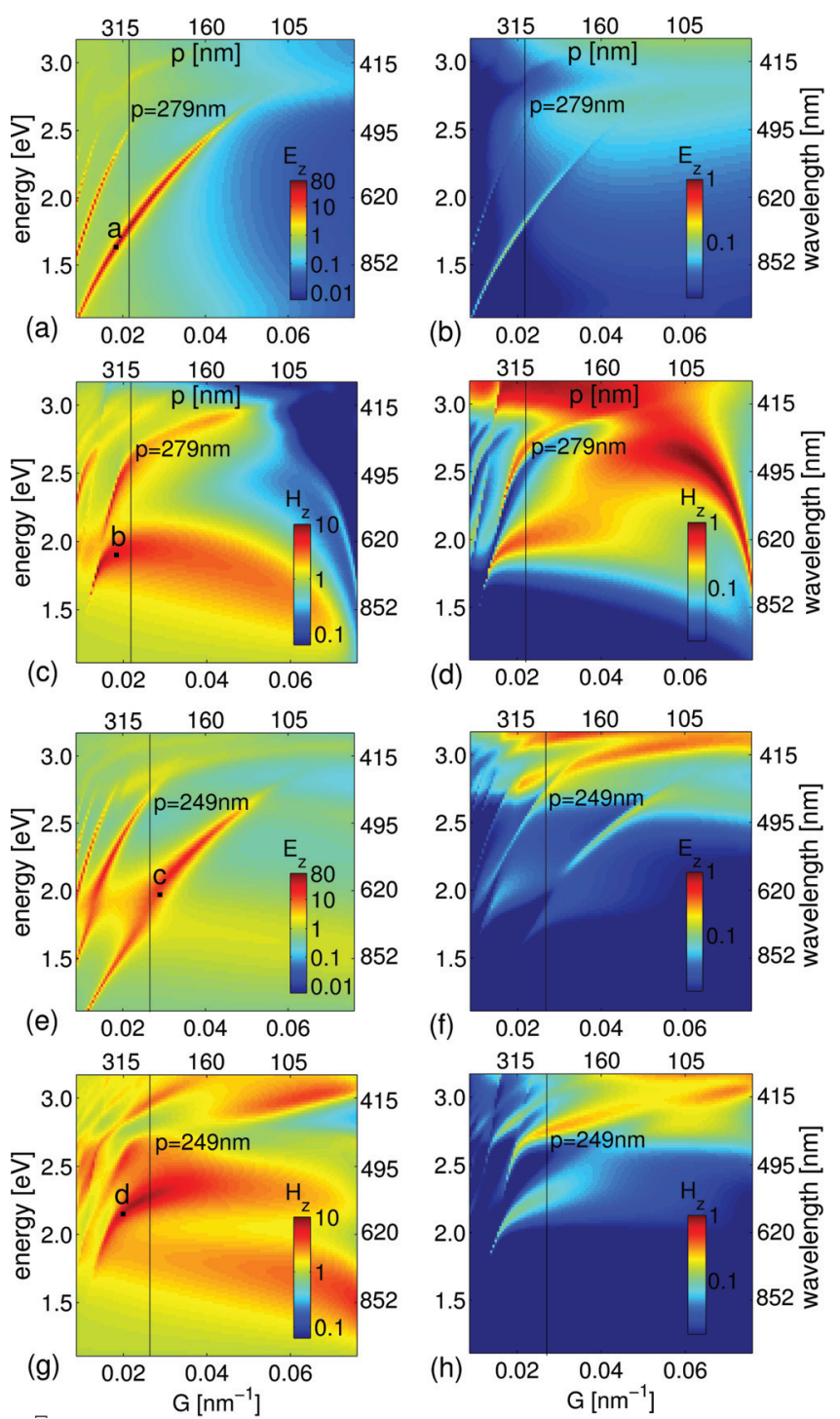

FIG. 2. Left column: Maps of the absorption enhancements in a Si thin film $(a=50 \mathrm{~nm})$ as a function of reciprocal lattice constant $G=2 \pi / p$ and photon energy $\hbar \omega$. (a) and (c): Results for Ag strips and $E_{z} / H_{z}$. For example: Results for Si strips. The highest short-circuit current is indicated by a vertical line ( $p=279 \mathrm{~nm}$ for $\mathrm{Ag}$ and $p=249 \mathrm{~nm}$ for $\mathrm{Si})$. For field patterns associated with points a-d, see panels (a)-(d) in Fig. 3. Right column: Plots of corresponding relative losses in the strips for the $\mathrm{Ag}$ and $\mathrm{Si}$ cases, respectively.

and metal strips seem to generate a similar enhancement pattern and number of slab-waveguide modes (cf. Figs. 2(a) and 2(e) and 2(c) and 2(g)), but the enhanced modes in the case of $\mathrm{Si}$ strips spread over wider intervals. Finally, if the enhancement plots are made for $\mathrm{SiO}_{2}$, they show an almost uniform distribution of a light green color corresponding to a performance slightly better than for a bare surface and only dim indications of first and second order mode patterns for the two polarizations can be seen. The modes are not well localized because the refractive index contrast between $\mathrm{SiO}_{2}$ and air is relatively small.

The absorption enhancements from Figs. 2(a), 2(c), 2(e), and $2(\mathrm{~g})$ indicate that somewhat similar slab-waveguide modes are generated for both metal and $\mathrm{Si}$ strips, i.e., the waveguide is only perturbed weakly by the addition of the dielectric or metallic nanostructuring. In order to compare them, four representative modes are plotted in 

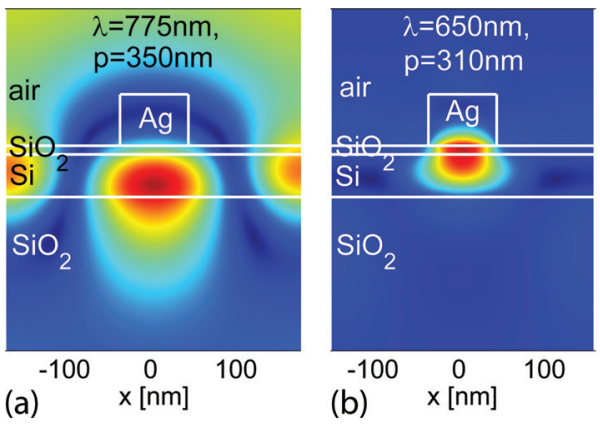

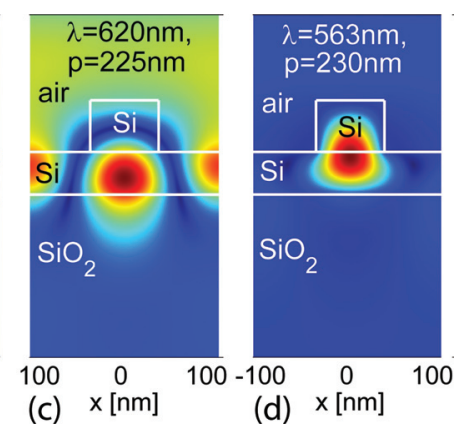

FIG. 3. Normalized field patterns $\left|E_{z}\right| /\left|E_{0}\right|$ and $\left|H_{z}\right| /\left|H_{0}\right|$, with (a)-(d) associated with points a-d indicated in Fig. 2. (a) and 2(b) are for Ag strips and (c) and (d) illustrate coupling to similar slab-waveguide modes for Si strips.
Figs. 3(a)-3(d) — corresponding to the four points marked in Figs. 2(a)-2(d). The values for the cell period $p$ and the optical wavelength $\lambda$ are indicated in each case. Pairwise, the modes in metal and Si gratings are very similar. When the modes for Si strips are compared to the ones above for $\mathrm{Ag}$, it is clear that the slab-waveguide modes of the same order and with similar field patterns can be generated no matter if the strips are formed by $\mathrm{Si}$ or metal. Hence, the enhanced absorption for this particular case is driven by grating effects, rather than plasmonic field enhancement. The optical field does not overlap much with the metal, but even small overlaps cause significant Ohmic loss. The overlap between the optical field and the Si strip is in general larger than for the metal, but still less energy is dissipated in this case.

In order to compare the broadband performance of the solar cell for the five different strip materials, the normalized short-circuit current is plotted as function of the cell period in Fig. 4(a). The shape of the curve for Ag is similar to the one from Ref. 7 and its maximum value $141 \%$ is found around $p=279 \mathrm{~nm}$ (compared to $143 \%$ and $p=295 \mathrm{~nm}$ (Ref. 7)). We use the standard AM1.5 (air mass) spectrum for the solar input. The performance for $\mathrm{Al}$ is similar to $\mathrm{Ag}$, whereas $\mathrm{Au}$ does not provide any enhancement of the normalized short-circuit current compared to the bare cell, which is mainly due to higher values of the imaginary part of $\varepsilon_{r}$ for the shorter wavelengths. However, Si performs better than the three metals for all cell periods, and it is better than the bare cell for almost the entire period interval considered. The curve reaches the highest value $268 \%$ for $p=249 \mathrm{~nm}$, and the enhancement is, therefore, 4 times larger than for the best performance of the metals. When using $\mathrm{SiO}_{2}$ strips, the normalized short-circuit current is slightly better than the bare surface for the entire interval, but $\mathrm{Si}, \mathrm{Ag}$, and $\mathrm{Al}$ still reach higher maximum values.
To ensure that the better performance of $\mathrm{Si}$ is not governed by strongly localized resonances, a study of the dependence of strip thickness $t$ is performed for $\mathrm{Ag}$ and $\mathrm{Si}$. In Fig. 4(b), the best point from the normalized short-circuit current graphs is plotted for a number of values of $t$. The two points marked with a circle in Fig. 4(a), therefore, correspond to the points marked with a circle in Fig. 4(b) for $t=60 \mathrm{~nm}$. The individual value of the cell period is indicated for each point. This study again confirms that Si performs better than the metals. Other geometric parameters (like, e.g., the thickness of the $\mathrm{SiO}_{2}$ film between metal and $\mathrm{Si}$ ) could likewise be optimized, however, our goal here is not to find the absolute optimum, but rather to illustrate the importance and potential gain from considering purely dielectric alternatives to plasmonic gratings.

In summary, a theoretical study of a periodic thin-film solar cell has been presented, where strips of $\mathrm{Ag}, \mathrm{Au}, \mathrm{Al}, \mathrm{Si}$, and $\mathrm{SiO}_{2}$ on top of the cell have been employed to enhance the absorption in a Si layer. It is shown that similar enhancements can be obtained for strips of metals and Si because similar localized mode effects are generated in the structure. However, less energy is lost in the Si strips and, therefore, the enhancements are in general greater and less dependent on cell dimensions and wavelength. This leads to larger values of the normalized short-circuit current for the Si strips. $\mathrm{SiO}_{2}$ strips only show slightly better performance compared to a bare surface because the refractive index contrast is too low to support localized modes. The study shows that for this particular device, a purely dielectric grating outperforms the plasmonic-based counterpart, primarily due to decreased Ohmic losses. Hence for the particular geometry, we do not observe any of the advantages usually associated with metallic gratings. Other test cases have led to similar conclusions although we cannot rule out the possible existence of cases
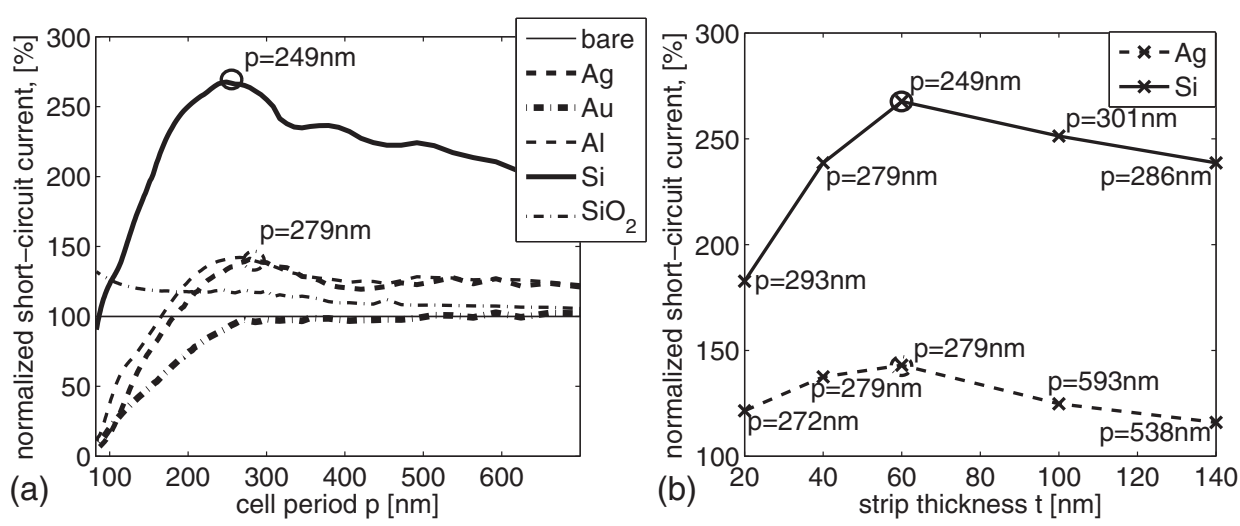

FIG. 4. (a) The short-circuit current (normalized to bare structure) as function of the period $p$ for the 5 different strip materials. (b) Short-circuit current (normalized to bare structure) as function of the thickness $t$ for Ag and Si strips. Each indicated point corresponds to the best value found on the curve from a study over the period interval used in (a). 
where plasmon enhanced surfaces perform better than purely dielectric ones. In general however, we conclude that when evaluating the potential of absorption enhancements for plasmonic structures, attention should be paid to dielectric surface structuring as well in order to make technologically sensible comparisons and ensure the best possible technological solutions.

This work received support from the Villum Foundation, the Danish Center for Scientific Computing (DCSC), and the CASE initiative, funded by the Danish Ministry of Science, Technology and Innovation. The authors are thankful to Sanshui Xiao for enlightening discussions.

${ }^{1}$ T. W. Ebbesen, H. J. Lezec, H. F. Ghaemi, T. Thio, and P. A. Wolff, Nature (London) 391, 667-669 (1998).

${ }^{2}$ F. J. García de Abajo, Rev. Mod. Phys. 79, 1267-1290 (2007).

${ }^{3}$ J. N. Anker, Nature Mater. 7, 442-453 (2008).
${ }^{4}$ J. A. Schuller, E. S. Bernard, W. Cai, Y. C. Jun, J. S. White, and M. L. Brongersma, Nature Mater. 9, 193-204 (2010).

${ }^{5}$ H. R. Stuart and D. G. Hall, Appl. Phys. Lett. 69, 2327-2329 (1996).

${ }^{6} \mathrm{H}$. A. Atwater and A. Polman, Nature Mater. 9, 205-213 (2010).

${ }^{7}$ R. A. Pala, J. White, E. Barnard, J. Liu, and M. L. Brongersma, Adv. Mater. 21, 3504-3509 (2009).

${ }^{8}$ D. Derkacs, S. H. Lim, P. Matheu, W. Mar, and E. T. Yu, Appl. Phys. Lett. 89, 093103 (2006).

${ }^{9}$ K. R. Catchpole and A. Polman, Opt. Express 16, 21793-21800 (2008).

${ }^{10}$ L. A. Weller-Brophy and D. G. Hall, J. Opt. Soc. Am. A 2, 863-871 (1985).

${ }^{11}$ L. Cao, P. Fan, A. Vasudev, J. White, Z. Yu, W. Cai, J. Schuller, S. Fan, and M. Brongersma, Nano Lett. 10, 439-445 (2010).

${ }^{12}$ COMSOL Reference Manual for comsol 3.5. COMSOL AB, Stockholm.

${ }^{13}$ R. Syms and J. Cozens, Optical Guided Waves and Devices, 1st ed. (McGraw-Hill, New York, 1992).

${ }^{14}$ U. Basu and A. Chopra, Comput. Methods Appl. Mech. Eng. 192, 1337-1375 (2003).

${ }^{15}$ Optical properties of silicon, Virginia Semiconductor Inc, www.virginiasemi.com.

${ }^{16}$ B. Brixner, J. Opt. Soc. Am. 57, 674-676 (1967).

${ }^{17}$ A. D. Rakić, A. B. Djuriši, J. M. Elazar, and M. L. Majewski, Appl. Optics 37, 5271-5283 (1998). 